\title{
The friction, mobility and transfer of tribological films: potassium chloride and ferrous chloride on iron
}

\author{
Feng Gao, Peter V. Kotvis, W.T. Tysoe* \\ Department of Chemistry and Laboratory for Surface Studies, University of Wisconsin-Milwaukee, Milwaukee, WI 53211, USA
}

Received 23 April 2003; accepted 16 June 2003

\begin{abstract}
The tribological properties of $\mathrm{FeCl}_{2}$, measured using an ultrahigh vacuum tribometer, are compared with those of KCl. The friction coefficient of an $\mathrm{FeCl}_{2}$ film evaporated onto iron in ultrahigh vacuum decreases to $\sim 0.08$ after the deposition of a film $\sim 40 \AA$ thick. This value is in good agreement with that measured for reactively formed $\mathrm{FeCl}_{2}$ films in a pin and v-block apparatus. The contact resistance also increases at the same $\mathrm{FeCl}_{2}$ thickness as that at which the friction coefficient reaches its minimum value suggesting that this corresponds to the completion of the first monolayer as found previously for $\mathrm{KCl}$. Comparison of the friction coefficients and contact resistances for a second pass suggests that the film is mobile during rubbing in both cases. It is found that repeated rubbing in the $\mathrm{case} \mathrm{FeCl} \mathrm{Feads}_{2}$ to a reduction in friction coefficient to $\sim 0.015$ which is shown to be due to the formation of a transfer film on the tribotip. In contrast, no such reduction is found for a $\mathrm{KCl}$ film up to 40 cycles, implying that no transfer film is formed in that case. It is also found that, while friction reduction requires the surface to be completely covered by the halide film, suppression of damage in the iron requires the deposition of films thicker than $\sim 500 \AA$.
\end{abstract}

(C) 2003 Elsevier B.V. All rights reserved.

Keywords: Halide films; $\mathrm{KCl} ; \mathrm{FeCl}_{2}$; Ultrahigh vacuum tribometer; Friction coefficient; Film mobility; Transfer films; Atomic force microscopy; Extreme-pressure lubrication

\section{Introduction}

We have shown previously that an extreme-pressure film consisting primarily of $\mathrm{FeCl}_{2}$ is formed reactively when using model extreme-pressure lubricants consisting of methylene chloride, chloroform or carbon tetrachloride dissolved in a poly $\alpha$-olefin $[1,2]$. These experiments were performed in a pin and v-block apparatus where friction coefficients were found to be $(11 \pm 1) \times 10^{-2}$ (for a film formed from methylene chloride [3]) and $(7.1 \pm 0.2) \times 10^{-2}$ (for a film from chloroform or carbon tetrachloride [4,5]). The mean contact pressure during this experiment is between 500 and $1000 \mathrm{MPa}$ with a linear sliding speed of $9.6 \times 10^{-2} \mathrm{~m} / \mathrm{s}$. In order to obtain a fundamental understanding of the frictional behavior of thin inorganic films on iron, we have studied a number of alkali halides deposited onto clean iron in ultrahigh vacuum $[6,7]$. While these have cubic structures, and are therefore different from the layered structure of $\mathrm{FeCl}_{2}$ [8], they do offer the advantage of having identical crystal structures to each other, thus allowing variations in tribological behavior to be related to their mechanical properties

\footnotetext{
* Corresponding author. Tel.: +1-414-229-5222; fax: +1-414-229-5036. E-mail address: wtt@uwm.edu (W.T. Tysoe).
}

without their crystal structures varying. We have measured the friction coefficients of a number of alkali halide films on iron and found, in general, that the deposition of a few tens of Ångstroms of these halides substantially reduces the interfacial friction coefficient from $\sim 2$ for clean iron to values less than $\sim 0.6$ [7]. Addition of more alkali halide, up to a total thickness of $\sim 2000 \AA$, has no further significant effect on the friction coefficient. These values of limiting friction coefficient of the various alkali halides scale linearly with their Knoop hardnesses in accord with expectations from Bowden and Tabor $[9,10]$ theory for thin films of a soft material deposited onto a harder substrate [7]. This condition is fulfilled in these cases since all of these halides have Knoop hardnesses less than $200 \mathrm{MPa}[11,12]$, while that of the pure iron substrate is almost $700 \mathrm{MPa}$ [6]. It was also demonstrated that the reduction in friction coefficient of a film of $\mathrm{KCl}$ on iron coincided with the complete coverage of the surface with halide [6]. In this case the proportion of bare iron surface was measured by titrating it with deuterium, which selectively adsorbs on iron but not on the halide [13]. These experiments were carried out using a single pass on a surface freshly prepared in ultrahigh vacuum where the tungsten carbide tribopin had been cleaned by heating in ultrahigh vacuum between each experiment. It is, however, well known 
that transfer films are often formed in tribological contacts $[14,15]$. This therefore raises the question of whether such transfer films might be formed in these single-pass experiments, and whether this might affect the tribological behavior. This question is addressed here for model films consisting of both $\mathrm{KCl}$ and $\mathrm{FeCl}_{2}$. As noted above, these materials have completely different crystal structures, where $\mathrm{KCl}$ adopts the cubic sodium-chloride-like structure, while ferrous chloride has a layered rhombohedral $\mathrm{CdCl}_{2}$ structure (space group $R \overline{3} m$ ) [8]. The frictional properties of $\mathrm{KCl}$ have been studied previously $[6,13]$ and $\mathrm{FeCl}_{2}$ is the predominant component of tribological films formed when using chlorinated hydrocarbon extreme-pressure additives [1,2,16-20]. Experiments are carried out in ultrahigh vacuum using a pin-on-disk configuration using a ball (tungsten carbide) of radius $6.35 \times 10^{-3} \mathrm{~m}$, where the load varies between 0.29 and $1.2 \mathrm{~N}$, corresponding to maximum Hertzian pressures of $\sim 420-670 \mathrm{MPa}$, respectively [21]. This is within the range of pressures in the pin and v-block apparatus, although the sliding speeds are considerably slower in the ultrahigh vacuum experiments $\left(4 \times 10^{-3} \mathrm{~m} / \mathrm{s}\right.$ versus $9.6 \times 10^{-2} \mathrm{~m} / \mathrm{s}$ ) to minimize heating in the tribocontact.

\section{Experimental}

Experiments were carried out in a stainless-steel, ultrahigh vacuum chamber operating at base pressures of $\sim 2 \times$ $10^{-10}$ Torr following bakeout, which has been described in detail elsewhere [6]. The chamber is equipped with an ultrahigh vacuum compatible tribometer which simultaneously measures normal forces, lateral forces and the contact resistance between the tip and substrate. It also contains a single-pass, cylindrical-mirror analyzer for Auger analysis of the surface, a quartz crystal microbalance (Sigma Instruments Model SQM-160) for measuring the thickness of the deposited film, an argon ion bombardment source for sample cleaning and an evaporation source for deposition of inorganic materials. This source has been described in detail elsewhere [22]. The potassium chloride and ferrous chloride (Alfa Aesar, 99.99\% purity) were loaded into the small alumina tube furnace and outgassed in ultrahigh vacuum prior to use. The clean iron foil sample $(0.1 \mathrm{~mm}$ thick, Aldrich, $99.999 \%$ pure) is attached to a sample manipulator where it is mounted onto a steel plate ( $0.5 \mathrm{~mm}$ thick) to provide a rigid base for the tribological measurements. Prior to mounting onto the steel plate, the sample is polished with $1 \mu \mathrm{m}$ diamond paste to a mirror finish. The sample can be resistively heated and it is cleaned using ion bombardment to remove any impurities (primarily carbon, chlorine and sulfur) and annealed to $1000 \mathrm{~K}$ prior to carrying out any tribological measurements. The iron sample following this treatment is almost atomically smooth and no significant surface features can be discerned using atomic force microscopy (AFM). The tribopin $\left(6.35 \times 10^{-3} \mathrm{~m}\right.$ radius $)$ is made from tungsten carbide containing some cobalt binder. This is cleaned by electron beam heating via a retractable filament that can be placed in front of the pin. An Auger analysis of the pin following this treatment is in accord with the bulk structure. Measurement of the pin topology using AFM shows that it is substantially rougher than the iron substrate having an approximately Gaussian height distribution with a width at half height of $\sim 2000 \AA$ [6].

\section{Results}

Fig. 1 displays the friction coefficient of an $\mathrm{FeCl}_{2}$ film evaporated onto iron measured as a function of film thickness for a single pass on the freshly prepared surface with an applied load of $0.29 \mathrm{~N}$ at a sliding speed of $4 \times 10^{-3} \mathrm{~m} / \mathrm{s}$. The friction coefficient drops rapidly from the clean surface value of $\sim 2$ to a limiting value of $(8 \pm 2) \times 10^{-2}$ after the deposition of $\sim 30 \AA$ of $\mathrm{FeCl}_{2}$ (see inset to Fig. 1 (四)). This behavior mimics that found previously for $\mathrm{KCl}$ where the friction coefficient similarly decreased to a limiting value (in that case $\sim 0.27$ ) after the deposition of $\sim 40 \AA$ of $\mathrm{KCl}[6]$.

The limiting value of friction coefficient of an evaporated $\mathrm{FeCl}_{2}$ film is in excellent agreement with that measured for

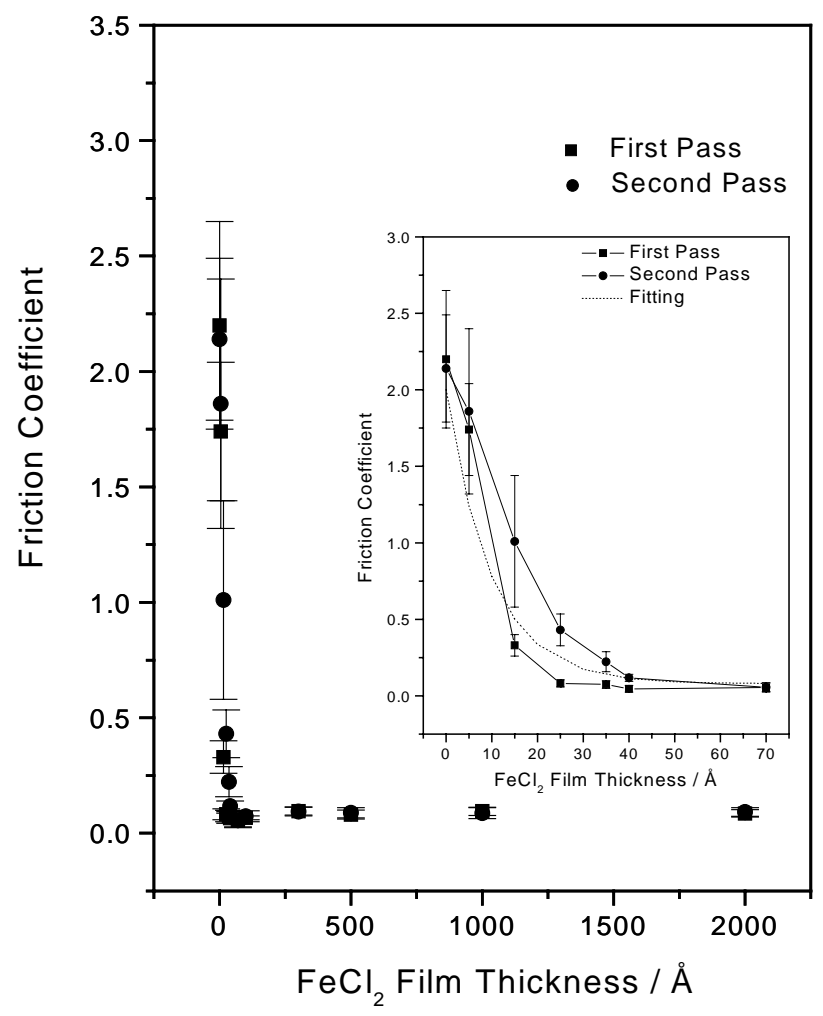

Fig. 1. Plot of friction coefficient vs. film thickness obtained following the evaporation of $\mathrm{FeCl}_{2}$ on clean iron up to a total film thickness of $2000 \AA$ using an applied load of $0.29 \mathrm{~N}$ with a sliding speed of $4 \times 10^{-3} \mathrm{~m} / \mathrm{s}$. Values are shown for the first pass on the freshly prepared film (ם) and for a second pass over exactly the same region as the first pass (O). Shown as an inset is an expansion of the region for low film thicknesses which shows a fit to Eq. (1) for the data for the first pass. 
reactively formed films using a pin and v-block apparatus [3-5]. This indicates that the frictional behavior of the evaporated thin film measured using the ultrahigh vacuum tribometer mimics that of $\mathrm{FeCl}_{2}$ films formed by reaction with the chlorinated hydrocarbon additive, in spite of the relatively large differences in sliding speed. It is interesting to note that the measured value of $\sim 0.08$ is much lower than the softest alkali halide measured $\left(\mathrm{KI}, H_{\mathrm{Knoop}}=49 \mathrm{MPa}\right)$, which yielded a friction coefficient of $\sim 0.2$ [7]. We were unable to find any similar hardness data for $\mathrm{FeCl}_{2}$, presumably because of its sensitivity to water and reactivity in air. Indeed, ex situ X-ray diffraction (XRD) measurements of the film reveal the formation of a dihydrate. Using the frictional data to calculate a hardness for $\mathrm{FeCl}_{2}$ yields a value of $\sim 20 \mathrm{MPa}$. In fact, because $\mathrm{FeCl}_{2}$ has a layered crystal structure, the friction coefficient is likely to be reduced because of the low shear strength of this material parallel to the layers of the crystal planes, rather than its low hardness.

It has been shown previously that the variation in friction coefficient with film thickness, assuming that the first monolayer is responsible for this decrease, is given by [13]:

$\mu-\mu_{\text {Film }}^{0}=\left(\mu_{\mathrm{Fe}}^{0}-\mu_{\text {Film }}^{0}\right) \mathrm{e}^{-\alpha t}$

where $\mu$ is the friction coefficient, $t$ the film thickness, $\mu_{\text {Film }}^{0}$ the limiting friction coefficient for large film thicknesses up to $2000 \AA\left(0.08 \pm 0.02\right.$ in this case), and $\mu_{\mathrm{Fe}}^{0}$ is the friction coefficient of clean iron. It should be emphasized that the decrease in friction coefficient to its limiting value at a film thickness of $\sim 30 \AA$ does not imply that this layer is $30 \AA$ thick, since second layer growth commences prior to the completion of the first layer; this thickness corresponds to the total film thickness at which the first monolayer saturates. A fit to the data shown as an inset in Fig. 1 for the first pass (ם) yields a value of $\alpha=$ $0.10 \pm 0.02 \AA^{-1}$. It has been shown that $\alpha=1 / t_{0}$ where $t_{0}$ is the first-layer film thickness [13] and the calculated value for $t_{0}$ for $\mathrm{FeCl}_{2}$ is therefore $10 \pm 2 \AA$. This is clearly an approximate value since the model assumes that the adsorption kinetics into the first as well as subsequent layers are identical. Nevertheless, it is instructive to compare this value with the lattice dimensions of $\mathrm{FeCl}_{2}$. As noted above, $\mathrm{FeCl}_{2}$ crystallizes into an approximately hexagonal unit cell with weakly interacting $\mathrm{FeCl}_{2}$ planes oriented perpendic-

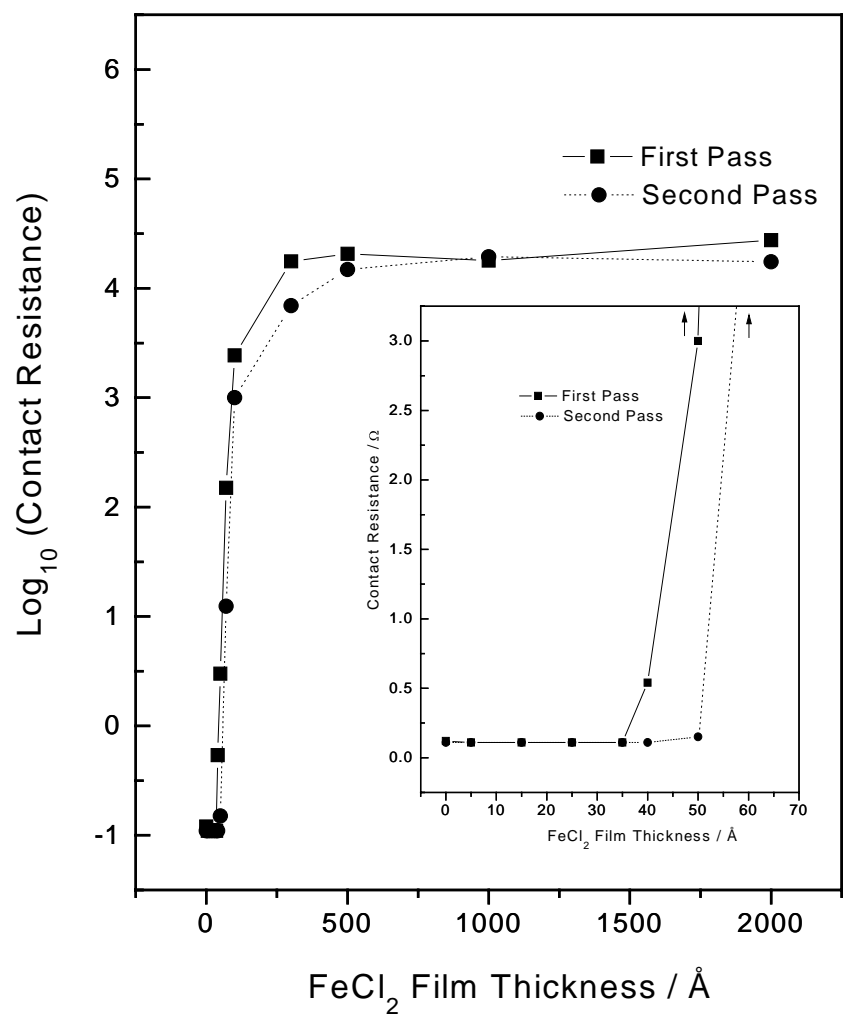

Fig. 2. Plot of average contact resistance during sliding measured as a function of film thickness up to a total film thickness of $2000 \AA$ obtained with an applied load of $0.29 \mathrm{~N}$ with a sliding speed of $4 \times 10^{-3} \mathrm{~m} / \mathrm{s}$. Values are shown for the first pass on the freshly prepared film (ם) and for a second pass over exactly the same region as the first pass (0). Shown as an inset is an expansion of the region for low film thicknesses.

ularly to the $c$ direction. The unit cell contains two such planes and the $c_{0}$ dimension is $17.536 \AA$ [8]. This yields an approximate thickness of a single $\mathrm{FeCl}_{2}$ layer of $\sim 10.4 \AA$ in good agreement with the measured value of $t_{0}$. This implies that a similar phenomenon occurs in the case of $\mathrm{FeCl}_{2}$ as found previously for $\mathrm{KCl}$; the presence of a single layer on the metal surface completely reduces the friction coefficient to its limiting value. Based on the measured value of $t_{0}$ for $\mathrm{FeCl}_{2}$, this is tentatively assigned to the deposition of a layer of $\mathrm{FeCl}_{2}$. The interlayer interaction in $\mathrm{FeCl}_{2}$ is weak, presumably resulting in a similarly weak interaction

(A)

(B)
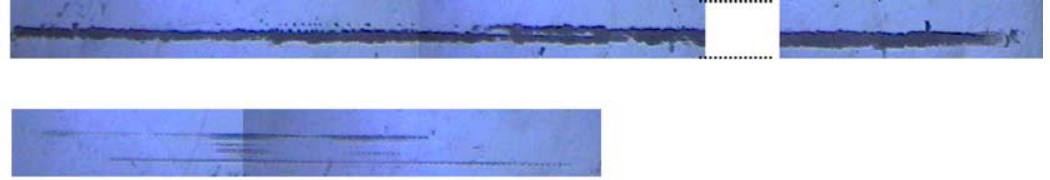

(C)

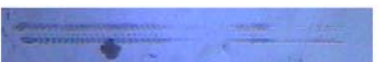

Fig. 3. Photographs of the wear scars for $\mathrm{FeCl}_{2}$ films evaporated onto clean iron in ultrahigh vacuum after sliding at $4 \times 10^{-3} \mathrm{~m} / \mathrm{s}$ with an applied load of $0.29 \mathrm{~N}$ and after washing the $\mathrm{FeCl}_{2}$ from the surface using deionized water to reveal the metal damage below. (A) Wear scar formed on clean iron, (B) the wear scar formed in a single scan after the deposition of $100 \AA$ of $\mathrm{FeCl}_{2}$, and (C) the wear scar formed in a single scan after the deposition of $200 \AA$ of $\mathrm{FeCl}_{2}$. 
between the layer and the tribotip and a low value of friction coefficient.

The corresponding plot of average contact resistance measured during the first pass is plotted as a function of film

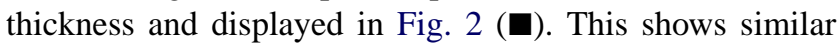
behavior as found previously for $\mathrm{KCl}$ deposited on iron [6]. The contact resistance remains low for film thicknesses below $\sim 35 \AA$ during the first pass, indicative of metal contact with the tribopin in this thickness range, in agreement with the notion that some bare metal remains exposed. This thickness correlates well with that at which the friction coefficient reaches its minimum value (Fig. 1). The contact resistance then rises rapidly with increasing film thickness to a limiting value of $\log _{10}$ (contact resistance $)=4.2 \pm 0.2$, which is the maximum value of contact resistance that can be measured since the a/d convertor saturates at this value.

After the friction coefficient and contact resistance had been measured on the freshly prepared surface, these values were measured in a second pass by sliding the pin once again over the same region in the same direction. Little difference is seen in the frictional behavior in the main plot in Fig. 1 for the first $(\square)$ and second $(\bullet)$ passes. However, if the scale is expanded for small film thicknesses (Fig. 1, inset) clear differences are detected between the friction coefficients in the first and second passes. This effect is confirmed by the contact resistance data in the inset in Fig. 2, which also reveal differences in contact resistance between the first $(\boldsymbol{\square})$ and second $(\bullet)$ passes. The lower contact resistance at higher coverages during the second pass (Fig. 2, inset) and the correspondingly higher friction coefficient (Fig. 1, inset) implies that material has been removed from the surface during the first pass and shows that, in the case of $\mathrm{FeCl}_{2}$, the evaporated film has some mobility in the contact region during sliding.

In order to gauge the anti-wear properties of the ferrous chloride film, the following experiment was carried out. The WC pin was slid over the clean surface in ultrahigh vacuum using a normal load of $0.29 \mathrm{~N}$ at $4 \times 10^{-3} \mathrm{~m} / \mathrm{s}$ to produce a wear scar on the iron surface. A similar experiment was carried out after depositing either 100, 200 or $500 \AA$ of $\mathrm{FeCl}_{2}$ on the surface, also in ultrahigh vacuum. Note that the friction coefficient in all of these cases has decreased to its minimum value of $\sim 0.08$ (Fig. 1). After removal of the sample from ultrahigh vacuum, the $\mathrm{FeCl}_{2}$ was washed from the surface using deionized water and the surface photographed. The resulting images are displayed in Fig. 3. The top image (Fig. 3A) shows a broad wear scar on the bare iron. The second two images show the presence of a wear scar only at the beginning of the sliding process while no wear scar is detected when $500 \AA$ of $\mathrm{FeCl}_{2}$ had been deposited onto the surface. The corresponding frictional traces as a function of position are displayed in Fig. 4A for $100 \AA$ of $\mathrm{FeCl}_{2}$ and in Fig. 4B for a $200 \AA$ thick film. It is evident that the stick-slip behavior is more pronounced at the beginning of the wear scar, in particular in the case of the $100 \AA$ film. The corresponding averaged contact resistance is plotted for
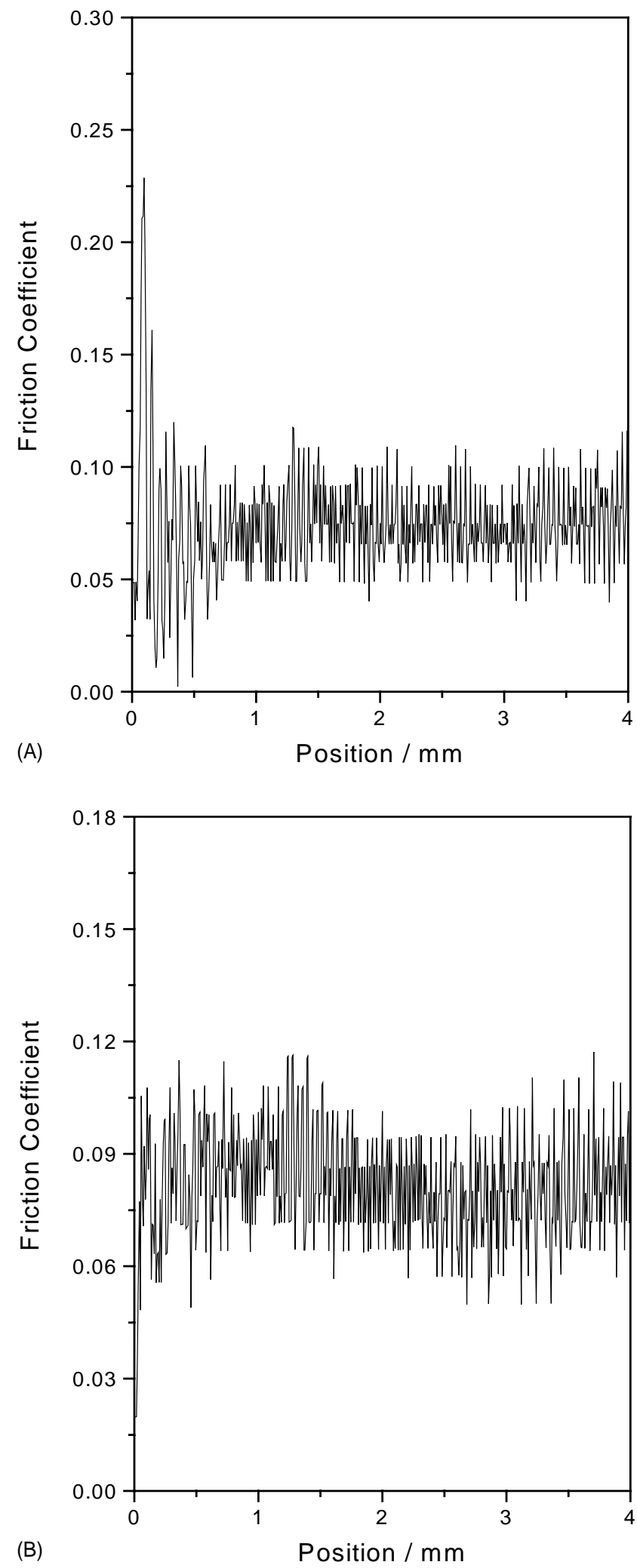

Fig. 4. Plot of friction coefficient vs. position following the deposition of (A) $100 \AA$ and (B) $200 \AA$ of $\mathrm{FeCl}_{2}$ on iron during sliding at $4 \times 10^{-3} \mathrm{~m} / \mathrm{s}$ with an applied load of $0.29 \mathrm{~N}$. 
a single pass for the iron surface covered with these films in Fig. 5A and B. In both of these cases, the contact resistance increases from a lower value to a higher value as sliding occurs. These data confirm that there is some mobility of the $\mathrm{FeCl}_{2}$ film during sliding.

AFM images were also collected of a surface covered with $200 \AA$ of $\mathrm{FeCl}_{2}$ after a single pass, under identical conditions as used to collect the images shown in Fig. 3, at the beginning of the wear scar (Fig. 6A), at the end of the wear scar (Fig. 6B), and in a region where no wear scar could be seen (Fig. 6C), again after the $\mathrm{FeCl}_{2}$ film had been removed using deionized water. The image of the worn region (Fig. 6A) shows a wear scar $\sim 70 \mu \mathrm{m}$ wide having substantial corrugations in the wear scar region due to interactions between the tribopin and the surface. For comparison, the Hertzian contact diameter under a load of $0.29 \mathrm{~N}$ is $36.5 \mu \mathrm{m}$ yielding a maximum Hertzian pressure of $420 \mathrm{MPa}$ compared to the measured Knoop hardness of the iron of $690 \mathrm{MPa}$ such that the width calculated assuming plastic deformation using the hardness of iron is $23.1 \mu \mathrm{m}$. An image of the end of the wear scar is shown in Fig. $6 \mathrm{~B}$ revealing that the corrugations found at the beginning of the wear scar persist until the end, but terminate quite abruptly, and the image in Fig. 6C shows minimal damage where no wear scar is detected in Fig. 3.

In addition to mobility within the film during sliding found above, it is possible that material is also transferred to the pin during sliding, resulting in the formation of a "transfer film" $[14,15]$. This was tested by measuring the friction coefficient during repeated passes, each in the same direction. Note that the data presented above suggest that material redistribution during sliding occurs after just the first few passes. This experiment was carried out using a $500-\AA$ thick $\mathrm{FeCl}_{2}$ film deposited onto iron using an applied load of $0.29 \mathrm{~N}$ at a sliding speed of $4 \times 10^{-3} \mathrm{~m} / \mathrm{s}$ and the results are displayed in Fig. 7. The friction coefficient shows an initial slight decrease in the first few passes and subsequently remains constant at $0.060 \pm 0.005$ for approximately 20 scans. Over the next 10 scans, the friction coefficient decreases to a minimum of $1.5 \times 10^{-2}$ and remains remarkably constant at this low value. This value is within the range found for similar lamellar $\mathrm{MoS}_{2}$ films [23-26]. Sliding was terminated after 40 scans, following which two experiments were performed. First, the tribopin was moved to a fresh part of the surface without cleaning, and the resulting friction coefficient is shown in trace A where it has increased slightly to $\sim 1.7 \times 10^{-2}$. Second, the tribopin was heated in ultrahigh vacuum and then slid in the original track. The resulting friction coefficient trace is marked $\mathrm{B}$ and shows that the friction coefficient increases to $\sim 0.08$. These experiments clearly indicate that material transferred to the tribopin is responsible for the reduction in friction coefficient to the lowest value of $\sim 1.5 \times 10^{-2}$ and is therefore indicative of the formation of a transfer film. Thus, the tribological experiments shown above are capable of detecting both lateral mobility of the film during sliding as well as
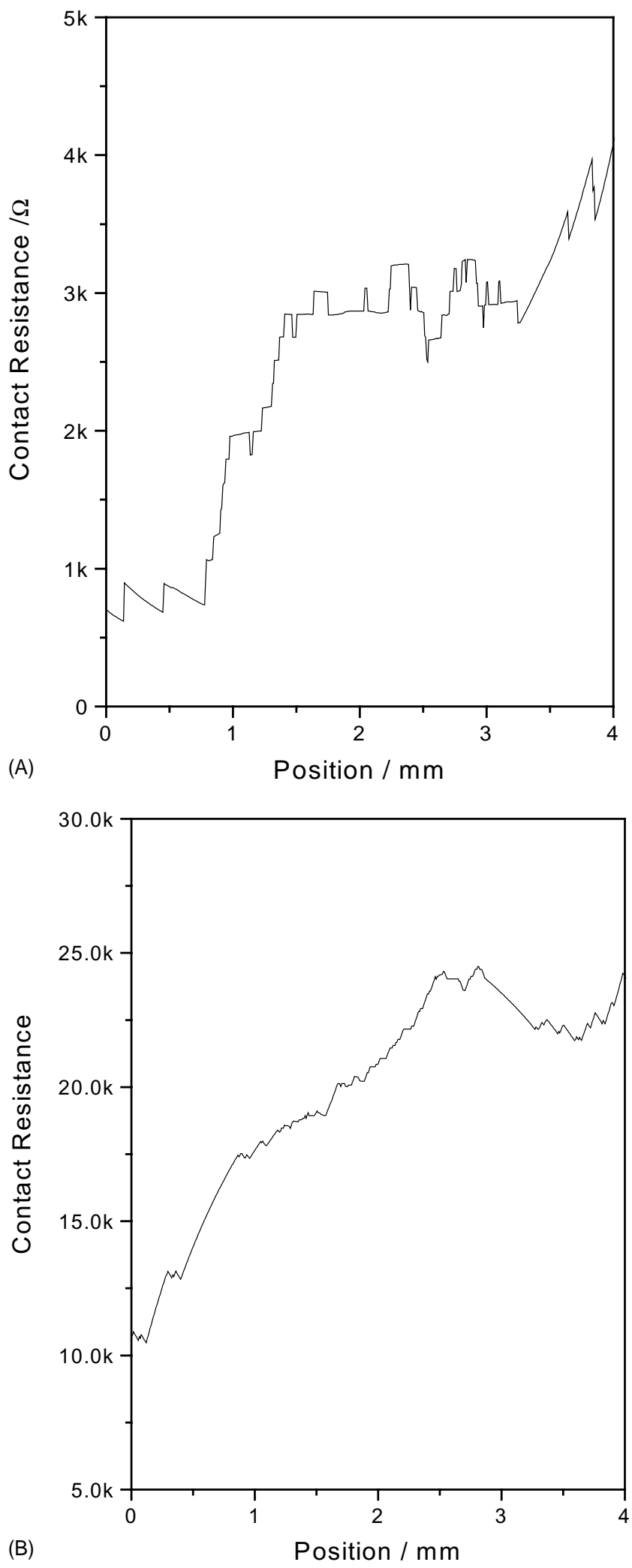

Fig. 5. Plot of averaged contact resistance vs. position following the deposition of (A) $100 \AA$ and (B) $200 \AA$ of $\mathrm{FeCl}_{2}$ on iron during sliding at $4 \times 10^{-3} \mathrm{~m} / \mathrm{s}$ with an applied load of $0.29 \mathrm{~N}$. 

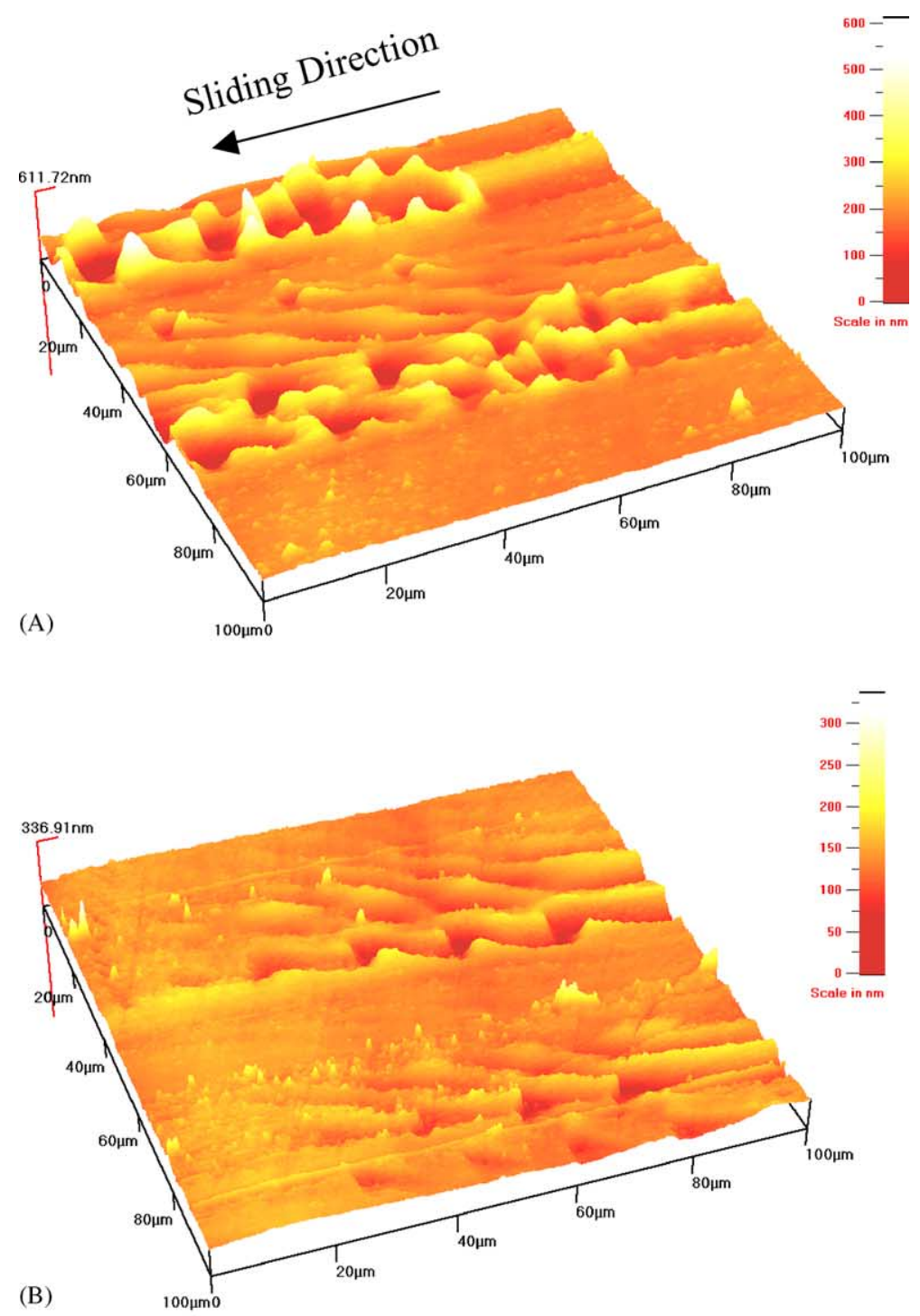

(B)

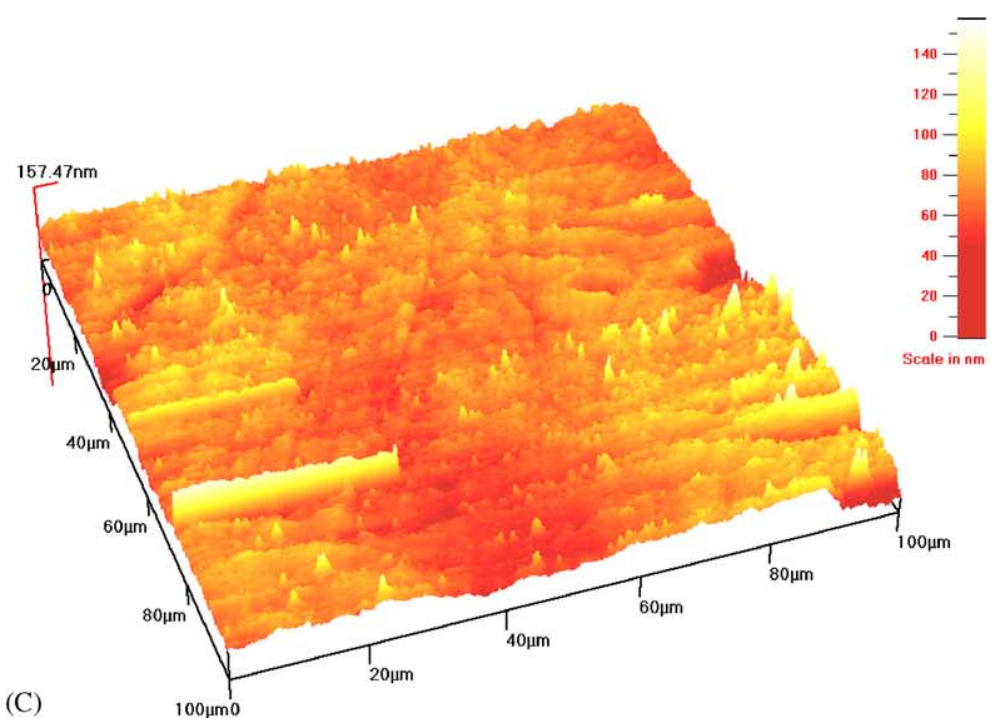

Fig. 6. Atomic force microscope (AFM) image of the wear scar on the iron after deposition of $200 \AA$ of $\mathrm{FeCl}_{2}$ on clean iron after a single scan at $4 \times 10^{-3} \mathrm{~m} / \mathrm{s}$ with an applied load of $0.29 \mathrm{~N}$ following removal of the $\mathrm{FeCl}_{2}$ with deionized water (A) at the beginning of the wear scar, (B) near the end of the wear scar, and (C) where no wear scar could be detected. 


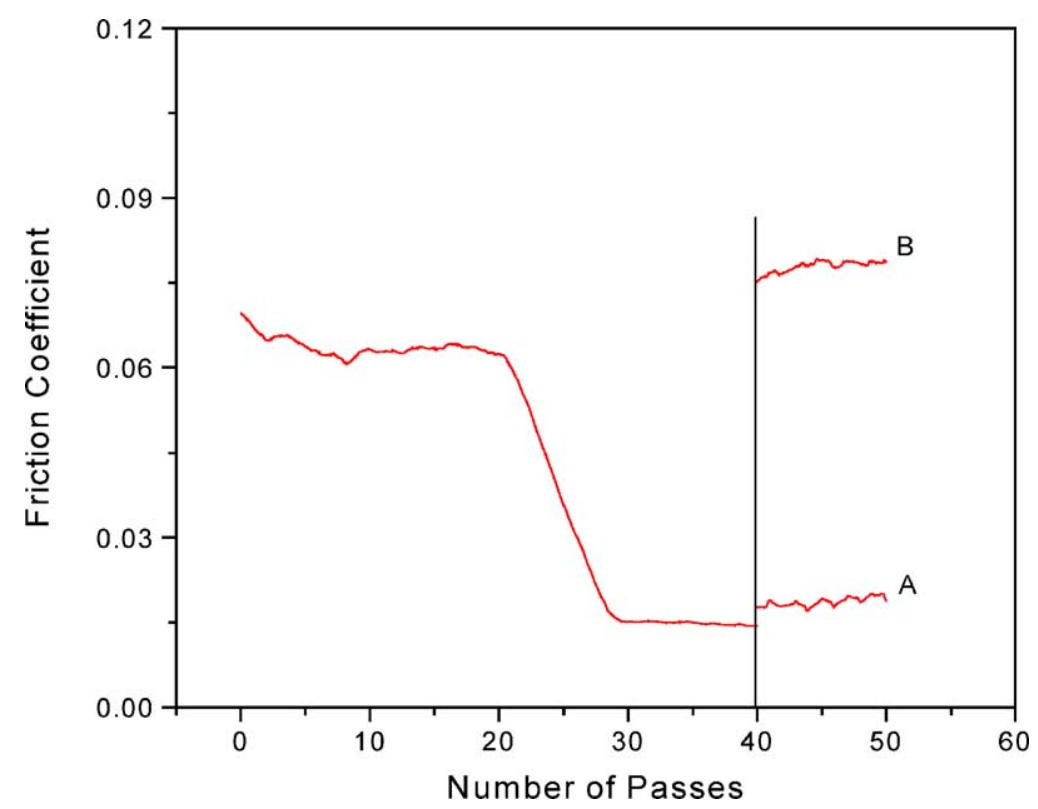

Fig. 7. Plot of friction coefficient as a function of number of passes following the deposition of $500 \AA$ of $\mathrm{FeCl}_{2}$ on clean iron with an applied load of $0.29 \mathrm{~N}$ and a sliding speed of $4 \times 10^{-3} \mathrm{~m} / \mathrm{s}$. The experiment was stopped after 40 passes. The pin was moved, without cleaning, to a new location on the surface and scanning continued (Trace A). Alternatively, the pin was then cleaned by e-beam heating and sliding was continued at the same point (Trace B).

transfer of material to the originally clean tungsten carbide surface.

These observations raise the question of whether similar effects occur when other non-laminar solid lubricating films, for example $\mathrm{KCl}$, are used. In order to answer this question, a similar series of experiments was carried out for $\mathrm{KCl}$ films deposited onto iron in ultrahigh vacuum. A significant amount of work has already been carried out to examine the tribological properties of these films where it has been shown that the friction coefficient during the first pass decreases from $\sim 2$ for the clean surface to $\sim 0.27$ following the deposition of a $\mathrm{KCl}$ film $\sim 40 \AA$ in thickness, and this was shown to be due to the completion of the first $\mathrm{KCl}$ layer measured to be $2.6 \pm 0.2 \AA$ thick $[6,13]$. A comparison of the friction coefficient between a first and second pass over the same area as a function of $\mathrm{KCl}$ film thickness is shown in Fig. 8. Data for the first pass ( $\mathbf{\square})$ are in good agreement with those published previously [6]. The friction coefficients for the second pass $(\bullet)$ are slightly higher than those for the first pass for film thicknesses less than $\sim 20 \AA$ indicating that some mobility occurs for the $\mathrm{KCl}$ film. The corresponding comparison of contact resistances are displayed in

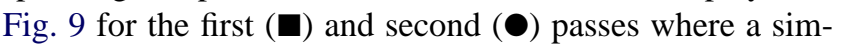
ilar phenomenon is found as for $\mathrm{FeCl}_{2}$ (Fig. 2) where the contact resistance is lower in the second pass than the first. This confirms that there is also some lateral mobility during rubbing in the non-laminar $\mathrm{KCl}$ film.

The wear resistance is measured by examining the nature of the iron surface after removing the $\mathrm{KCl}$ film using deionized water. The wear scars following the deposition of $100,200,500$ and $1000 \AA$ of $\mathrm{KCl}$ on iron after a single pass with a load of $0.29 \mathrm{~N}$ at a sliding speed of $4 \times 10^{-3} \mathrm{~m} / \mathrm{s}$

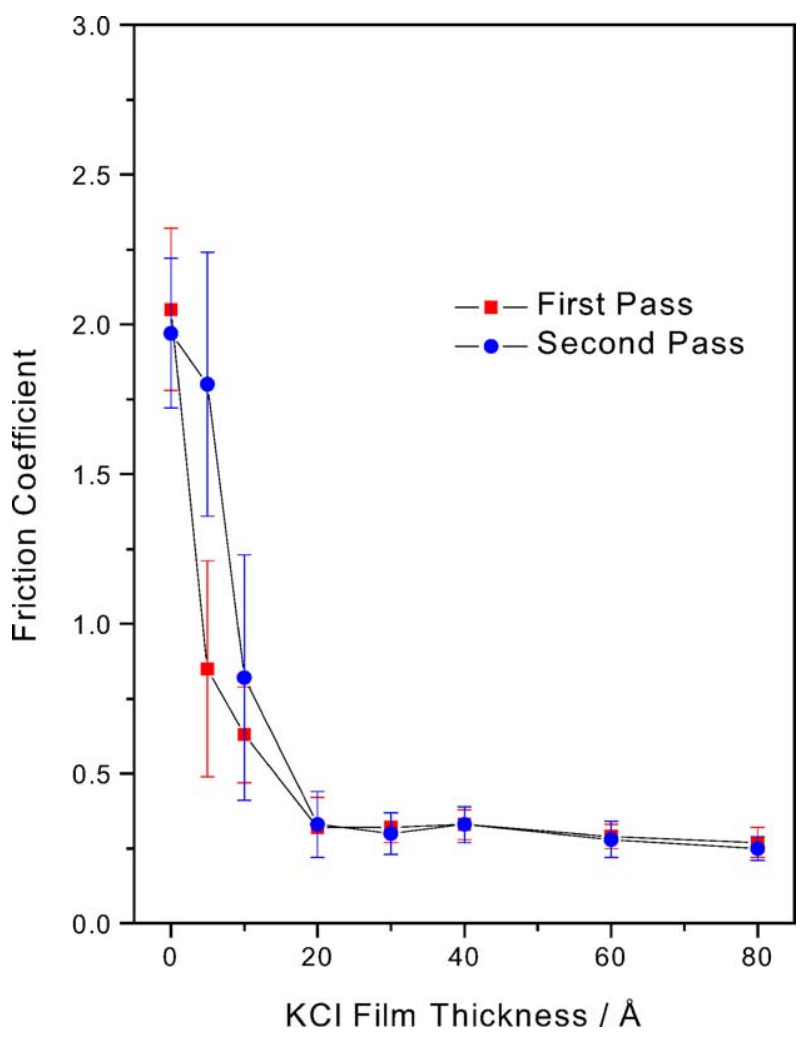

Fig. 8. Plot of friction coefficient vs. film thickness following the evaporation of $\mathrm{KCl}$ on clean iron up to a total film thickness of $80 \AA$ obtained with an applied load of $0.29 \mathrm{~N}$ with a sliding speed of $4 \times 10^{-3} \mathrm{~m} / \mathrm{s}$. Values are shown for the first pass on the freshly prepared film $(\boldsymbol{\square})$ and for a second pass over exactly the same region as the first pass 


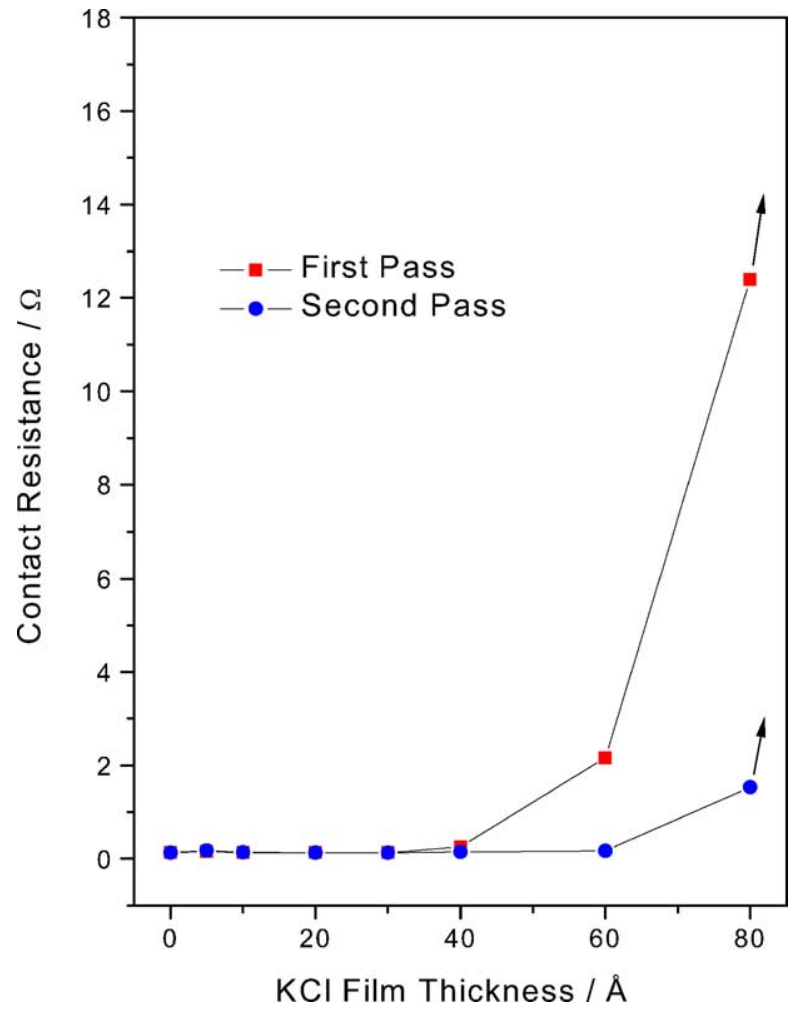

Fig. 9. Plot of contact resistance vs. film thickness following the evaporation of $\mathrm{KCl}$ on clean iron up to a total film thickness of $80 \AA$ obtained with an applied load on $0.29 \mathrm{~N}$ and a sliding speed of $4 \times 10^{-3} \mathrm{~m} / \mathrm{s}$. Values are shown for the first pass on the freshly prepared film (ם) and for a second pass over exactly the same region as the first pass (O).

are shown in Fig. 10B-E, respectively and compared with that on the clean surface in Fig. 10A. Surface damage is detected throughout the length of the region slid for film thicknesses up to $200 \AA$. This is in contrast to the behavior found for $\mathrm{FeCl}_{2}$ films where wear occurred only at the beginning of the sliding region (see Fig. 3). The analogous atomic force microscope images of the wear scar regions are displayed in Fig. 11A-E. Fig. 11A displays the end of the wear scar for clean iron for comparison and shows a wear scar width of slightly greater than $20 \mu \mathrm{m}$, and is in good agreement with that calculated by assuming plastic deformation $(23.1 \mu \mathrm{m})$. This image also reveals corrugations in the wear scar due to stick-slip behavior. Fig. 11B shows the wear scar when $100 \AA$ of $\mathrm{KCl}$ have been deposited onto the surface where significant wear is also seen. There are similar corrugations in the surface, although these are somewhat more striated than for the clean surface. It is evident that significant wears occurs on this surface although at this thickness, the friction coefficient has already decreased to its minimum value of $\sim 0.27$ [6]. The corresponding images of the wear scars after the deposition of $200 \AA$ (Fig. 11C) and $500 \AA$ (Fig. 11D) show a similarly striated behavior in the wear scars, which become slightly thinner as the film becomes thicker indicating some anti-wear behavior for the 500- $\AA$ thick film. Note that $\mathrm{FeCl}_{2}$ had completely suppressed wear by this film thickness. The wears scar formed after the deposition of $1000 \AA$ of $\mathrm{KCl}$ (Fig. 10E) shows a curious double wear scar where these are separated by $\sim 60 \mu \mathrm{m}$.

Finally, Fig. 12 shows the effect of repeated passes on the friction coefficient of a $1000-\AA$-thick $\mathrm{KCl}$ film using an applied load of $0.29 \mathrm{~N}$ with a sliding speed of $4 \times 10^{-3} \mathrm{~m} / \mathrm{s}$. This shows that the friction coefficient remains reasonably constant up to $\sim 40$ passes with perhaps a slight decrease during the first twenty passes. A similar set of experiments was carried out as for the $\mathrm{FeCl}_{2}$ film. That is, the tribopin was either slid over a new region of the $\mathrm{KCl}$-covered iron without heating the tribopin (Trace A) or heated and slid over the same region (Trace B). In contrast to the behavior seen for $\mathrm{FeCl}_{2}$ (Fig. 7), only slight differences are found in the resulting friction coefficient. This implies that there is no detectable transfer of $\mathrm{KCl}$ to the tribopin, even after 40 scans.

(A)

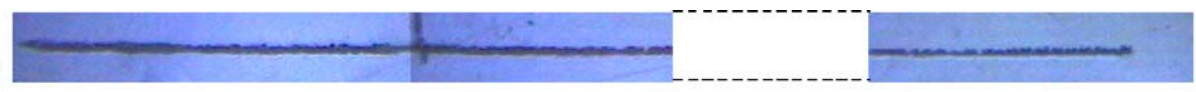

(B)

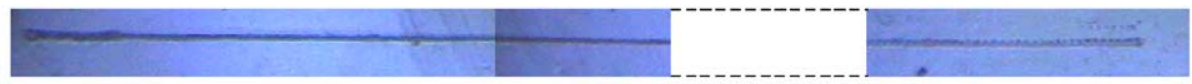

(C)

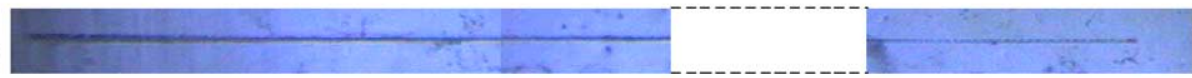

(D)

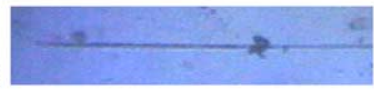

(E)

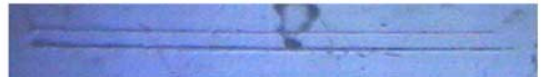

Fig. 10. Photographs of the wear scars of $\mathrm{KCl}$ films evaporated on clean iron in ultrahigh vacuum after sliding at $4 \times 10^{-3} \mathrm{~m} / \mathrm{s}$ with an applied load of $0.29 \mathrm{~N}$ and after washing the $\mathrm{KCl}$ from the surface using deionized water to reveal the metal damage below. (A) Wear scar formed on clean iron and the wear scars formed in a single scan after the deposition of (B) $100 \AA$, (C) $200 \AA$, (D) $500 \AA$, and (E) $1000 \AA$ of $\mathrm{KCl}$ on iron. 

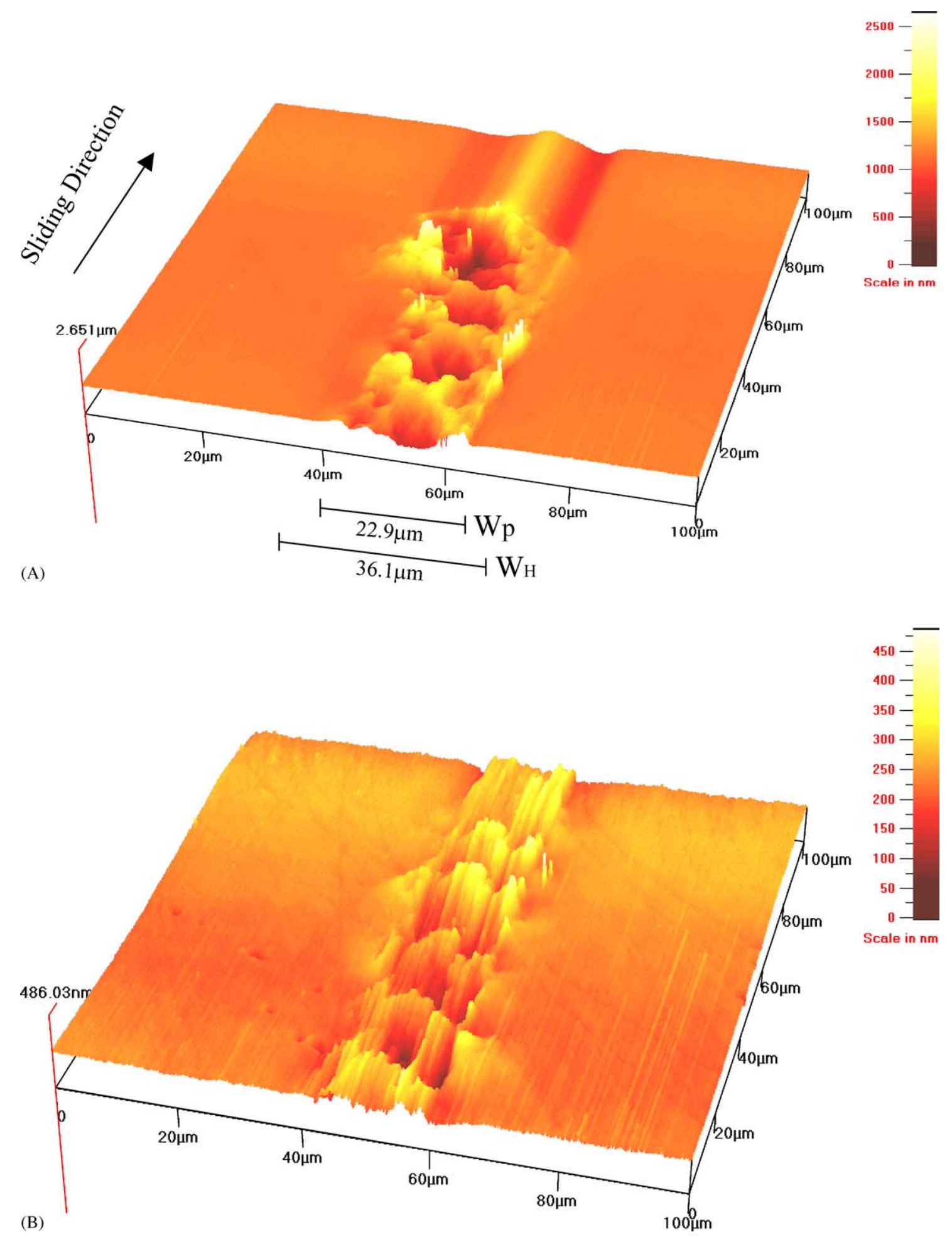

Fig. 11. Atomic force microscope images of $\mathrm{KCl}$ films evaporated onto clean iron in ultrahigh vacuum after sliding at $4 \times 10^{-3} \mathrm{~m} / \mathrm{s}$ with an applied load of $0.29 \mathrm{~N}$ and after washing the $\mathrm{KCl}$ from the surface using dionized water to reveal the metal damage below. (A) Wear scar formed on clean iron and the wear scars formed in a single scan after the deposition of (B) $100 \AA$, (C) $200 \AA$, (D) $500 \AA$, and (E) $1000 \AA$ of $\mathrm{KCl}$ on iron. 
(C)

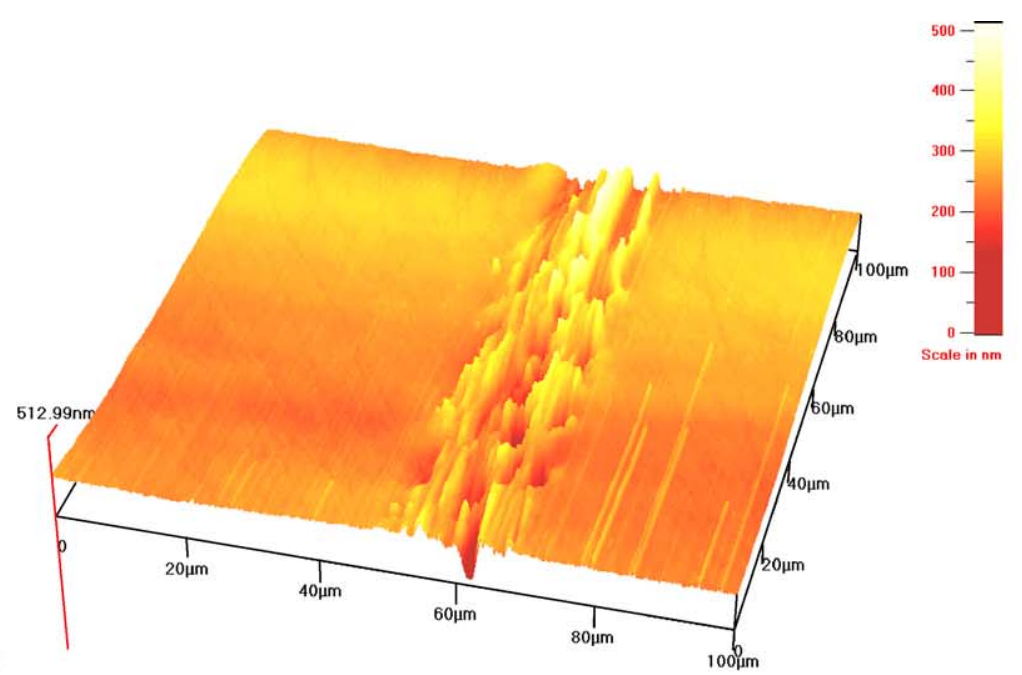

(D)
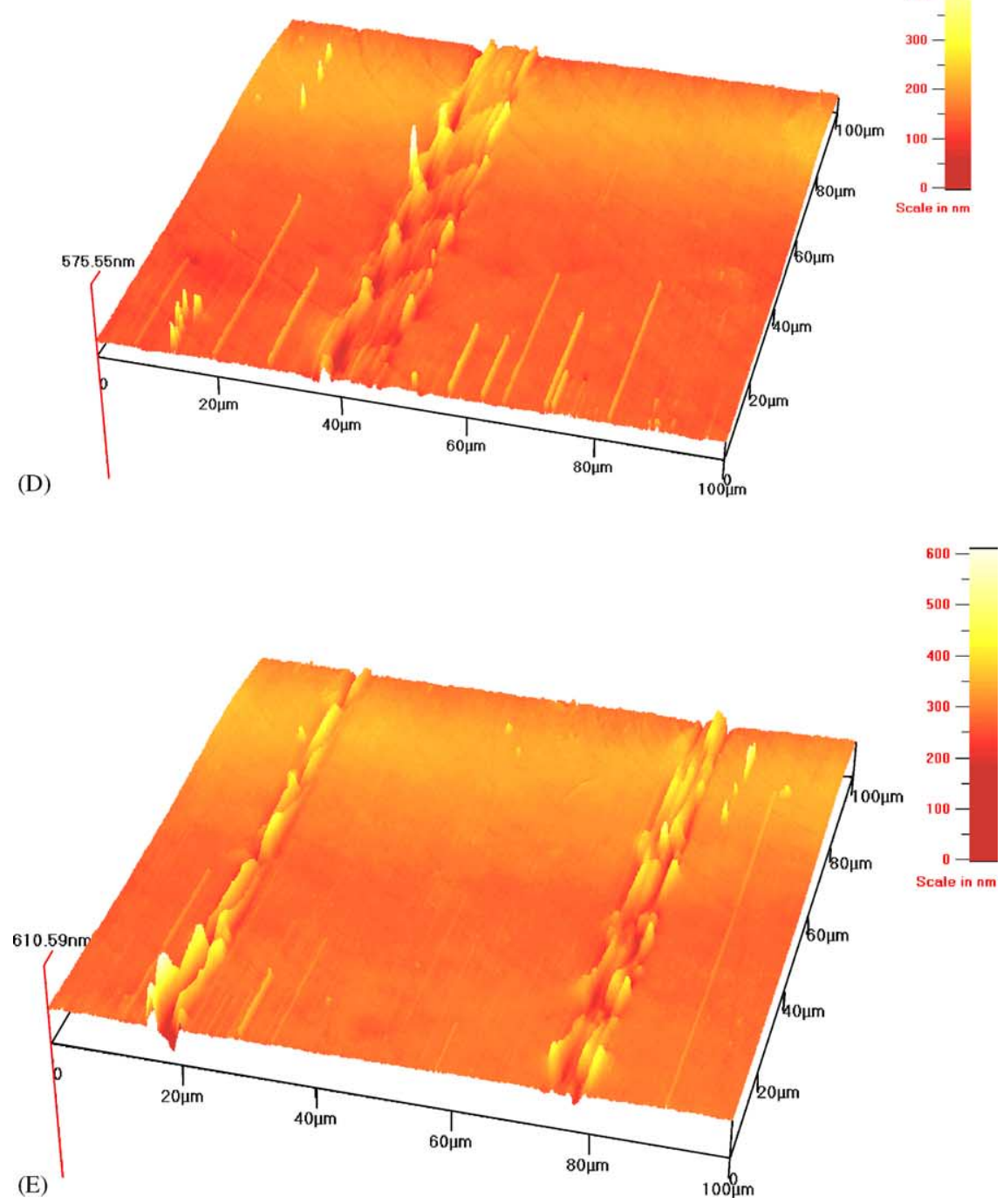

Fig. 11. (Continued). 


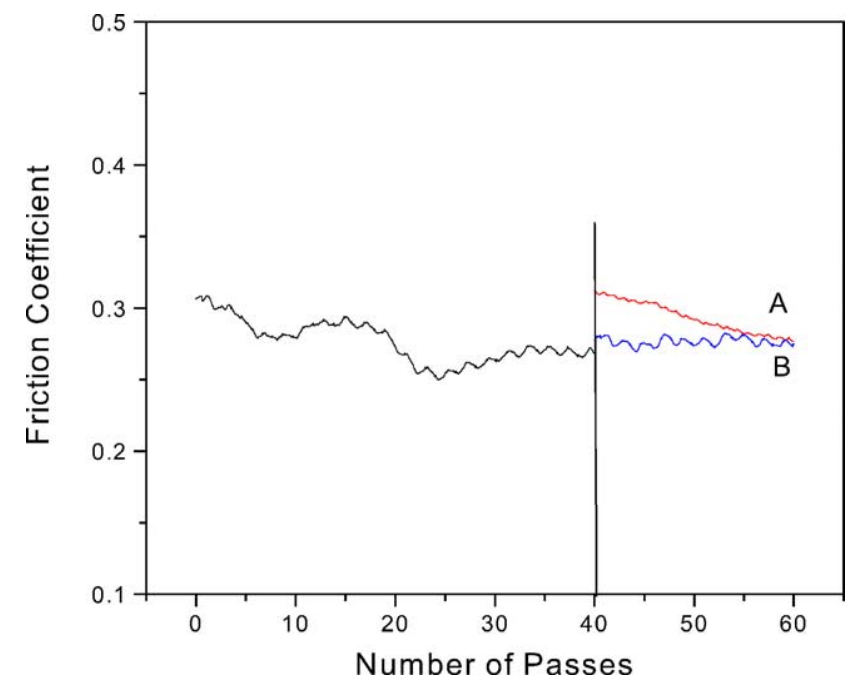

Fig. 12. Plot of friction coefficient as a function of number of passes following the deposition of $1000 \AA$ of $\mathrm{KCl}$ on clean iron with an applied load of $0.29 \mathrm{~N}$ and a sliding speed of $4 \times 10^{-3} \mathrm{~m} / \mathrm{s}$. The experiment was stopped after 40 passes. The pin was moved, without cleaning, to a new location on the surface and scanning continued (Trace A). Alternatively, the pin was then cleaned by e-beam heating and sliding was continued at the same point (Trace B).

\section{Discussion}

It is evident that the film thicknesses required for friction reduction and wear suppression are completely different. The completion of a first layer of $\mathrm{FeCl}_{2}$ approximately $10 \AA$ thick causes the friction coefficient to drop to its limiting value of $\sim 0.08$, while a first-layer $\mathrm{KCl}$ film of $\sim 2.6 \AA$ in thickness causes the friction coefficient to fall to a limiting value of $\sim 0.27$. It is evident, however, that significantly larger film thicknesses are required to suppress deformation of the surface where this is $\sim 500 \AA$ for $\mathrm{FeCl}_{2}$ and more than $\sim 1000 \AA$ for $\mathrm{KCl}$. This implies that in those cases where films are required just to lower the friction coefficient, such as extreme-pressure applications in metalworking in which wear must still take place, only a monolayer film needs to be deposited. Since relatively high surface temperatures are generally attained in such applications [19], the lubricant additives that provide these films have to form a monolayer during the lubrication process. Of course, since wear is occurring at the same time, the surface reaction should be sufficiently rapid to balance the wear rate by the maintenance of at least a monolayer film. In contrast, anti-wear films must be significantly thicker in order to completely suppress substrate damage where films apparently between 500 and $1000 \AA$ are required for $\mathrm{FeCl}_{2}$ and above $\sim 1000 \AA$ for $\mathrm{KCl}$. These values are of the same order of magnitude as the films formed from zinc dialkyl dithiophosphate (ZDDP), a well-known anti-wear additive $[27,28]$. In the experiments carried out here with a tungsten carbide ball and clean iron substrates, it has been shown that the iron substrate is much smoother than the tungsten carbide ball [6], which shows an approximately Gaussian height distribution with a width of $\sim 2000 \AA$. Some penetration of the film is noted from the contact resistance measurements for $\mathrm{FeCl}_{2}$ (Fig. 2), which does not reach its limiting value until $500 \AA$ of $\mathrm{FeCl}_{2}$ has been deposited. A similar behavior is found for $\mathrm{KCl}$ [6] where $\sim 1000 \AA$ of $\mathrm{KCl}$ must be deposited for the contact resistance to reach the limiting value. These thicknesses are similar to those required to suppress wear and suggests that the penetration of the film by the tips of even relatively few asperities leads to deformation of the substrate underneath. In contrast the friction coefficient is reduced to its minimum value by the completion of the first monolayer either of $\mathrm{FeCl}_{2}$ or $\mathrm{KCl}$ [6]. This may be because such few asperities penetrate the film that, although deformation still can occur with these fewer asperities, their total contact area, relative to that for the film-free surface, is so low that its effect on the friction coefficient cannot be distinguished within the accuracy of the experiments.

The friction coefficient of the $\mathrm{FeCl}_{2}$ film is rather low $(\sim 0.08)$ and likely reflects the layer structure of $\mathrm{FeCl}_{2}$, which is similar to that of $\mathrm{MoS}_{2}$, which exhibits a similarly low friction coefficient [23-26]. The values measured for the film evaporated onto iron in ultrahigh vacuum here are very similar to those found for reactively formed halide films [3-5].

It is clear that transfer films form from $\mathrm{FeCl}_{2}$ although this does not have a substantial effect on the friction coefficient until about 20 passes in the case of $\mathrm{FeCl}_{2}$, while no significant transfer film appears to form from $\mathrm{KCl}$. This implies that the effect of transfer films on the first pass even in the case of $\mathrm{FeCl}_{2}$ is insignificant and that transfer of material from the substrate to the pin does not unduly affect these tribological measurements. Interestingly, the frictional behavior of the $\mathrm{FeCl}_{2}$ and $\mathrm{KCl}$ films as a function of the number of passes is strikingly different. In the case of $\mathrm{KCl}$ films, the friction coefficient is relatively constant. The behavior with $\mathrm{FeCl}_{2}$ is completely different. A small initial decrease is observed during the first few passes, probably due to some $\mathrm{FeCl}_{2}$ redistribution on the iron foil within the contact region. The friction coefficient then remains constant for $\sim 20$ passes and then decreases almost linearly to reach its limiting value of $\sim 1.5 \times 10^{-2}$ in the next 10 passes, and remains constant thereafter (Fig. 7). It may be that the $\mathrm{FeCl}_{2}$ layers are initially rather randomly distributed within the film and are reoriented during sliding during the first 20 cycles [29]. Unfortunately, the degree of order of the $\mathrm{FeCl}_{2}$ films could not be measured ex situ using XRD since it rapidly reacted with water vapor from the air to form a dihydrate.

We finally address the question of the wear scar widths found during sliding in the presence of $\mathrm{FeCl}_{2}$ (Fig. 6) and $\mathrm{KCl}$ (Fig. 11). The maximum Hertzian pressure $\left(P_{0}\right)$ for a perfectly smooth ball of radius $6.35 \times 10^{-3} \mathrm{~m}$ at an applied load of $0.29 \mathrm{~N}$ used in all of the sliding experiments is $420 \mathrm{MPa}$ and is less than the Knoop hardness of iron, which has been measured at $690 \mathrm{MPa}$ [6]. However, slip-line theory analyses of rigid-perfectly-plastic bodies show that the 
contact area grows during sliding so that at the onset of sliding it has grown to approximately three times that value under just compression [21]. In addition, since the surface of the pin is microscopically rough with a topological height distribution of $\sim 2000 \AA$ [6], it is likely that the load will be supported at the tips of the pin asperities. This will affect the total apparent contact radius, which is dependent on a roughness parameter $\alpha=\sigma_{\mathrm{S}} / \delta_{0}$ where $\sigma_{\mathrm{S}}$ is the standard deviation of the Gaussian distribution of heights of the peaks on the surface and $\delta_{0}$ is the bulk compression at the center of the contact [21]. Note that $\sigma_{\mathrm{S}}$ refers to the distribution of the tips of the asperities, not to the topological height distribution which refers to all points and is therefore not equal to $2000 \AA$. For $\alpha=0$, the surface is perfectly smooth and the contact area is calculated using Hertzian theory for an elastic contact. As the roughness increases, so does the apparent contact radius and, for example reaches almost 1.5 times the Hertzian radius for $\alpha=1$. Measurement of the peak height distribution of the AFM image of the pin surface yields a value of $\left(\sigma_{\mathrm{S}}=5.0 \pm 0.1\right) \times 10^{-8} \mathrm{~m} \mathrm{[6]}$. The value of $\delta_{0}$ for a Hertzian contact under a load of $0.29 \mathrm{~N}$ is $5.1 \times 10^{-8} \mathrm{~m}$, so that $\alpha \approx 1$. This will yield a Hertzian contact radius that is $\sim 1.5$ times larger than for the smooth surface. In the case of plastic contact, this parameter is known as the adhesion index and is $\sim 2.3$ for iron under a load of $0.29 \mathrm{~N}$ [30]. Shown plotted on Fig. 11A, the AFM image of the wear scar for clean iron, are the calculated values of the contact width for plastic $\left(W_{\mathrm{P}}\right)$ and elastic $\left(W_{\mathrm{H}}\right)$ contacts. Given the above discussions, there is surprisingly good agreement between the width of the wear scar and that calculated for plastic deformation. This is likely to be fortuitous and the actual contact is likely to deform plastically in the center, but elastically towards the edges where the contact pressure decreases. As $\mathrm{KCl}$ is added to the surface, the wear scar region becomes narrower and the load is also supported by the halide layer and is only penetrated in the center where the pressures on the asperities are larger. Finally, after the deposition of $\sim 1000 \AA$ of $\mathrm{KCl}$, the central wear region disappears but the wear scar consists of two wear traces separated by $\sim 60 \mu \mathrm{m}$, presumably at the edge of the wear scar (Fig. 10E). A similarly wide wear scar is found following the deposition of $200 \AA$ of $\mathrm{FeCl}_{2}$ when wear is apparent at the beginning of the wear scar (Fig. 6A), and is also about $\sim 65 \mu \mathrm{m}$ wide. In the case of the $\mathrm{FeCl}_{2}$ film, there is a central striated region about $35 \mu \mathrm{m}$ wide and rougher ridges about $10 \mu \mathrm{m}$ wide at each side. The width of the central region corresponds approximately to the expected Hertzian width. Alternatively, complete ploughing of a film of thickness $t$ with a ball of radius $R$ will leave a wear track of radius $a$ where $a=$ $\sqrt{ }(2 t R)$. When the film is $200 \AA$ thick, $a$ is $31.2 \mu \mathrm{m}$, and for an $1000-\AA$ thick film it is $71.3 \mu \mathrm{m}$. These values agree well with the width of the central portion where some wear has occurred with the thin $\mathrm{FeCl}_{2}$ film, while this has been suppressed by the thicker $\mathrm{KCl}$ film. In both cases, however, additional wear appears to take place at the edges of the wear track. Note that all of these images have been collected after the film has been removed by deionized water and therefore represent the damage to the metal underneath.

\section{Conclusions}

The deposition of $\mathrm{FeCl}_{2}$ onto iron causes the friction coefficient to drop to a limiting value of $\sim 0.08$ in good agreement with values measured from $\mathrm{FeCl}_{2}$ films reactively deposited onto iron measured in a pin and v-block apparatus. Measurement of the variation in friction coefficient with film thickness suggests that this is due to the formation of a monolayer film of $\sim 10 \AA$ in thickness, in good agreement with the thickness of a $\mathrm{FeCl}_{2}$ layer. Comparing the friction coefficients and contact resistances for both $\mathrm{FeCl}_{2}$ and $\mathrm{KCl}$ films as a function of film thickness for the first and second passes indicates that there is some lateral mobility of the films during rubbing. It is also shown that the friction coefficient of the $\mathrm{FeCl}_{2}$ layer decreases to $\sim 1.5 \times 10^{-2}$ after about 30 rubbing cycles, an effect that is demonstrated to be due to the formation of a transfer film. In contrast, no such transfer film is apparent for $\mathrm{KCl}$.

It is also found for $\mathrm{KCl}$ films that damage in the substrate is only suppressed after $1000-2000 \AA$ have been deposited. This suggests that extreme-pressure films, which are required only to reduce friction, but not wear, need only be relatively thin (of the order of a few Ångstroms) while an anti-wear film must be much thicker.

\section{Acknowledgements}

We gratefully acknowledge support of this work by the Chemistry Division of the National Science Foundation under grant number CHE-9213988.

\section{References}

[1] T.J. Blunt, P.V. Kotvis, W.T. Tysoe, Tribol. Trans. 41 (1998) 117.

[2] T.J. Blunt, P.V. Kotvis, W.T. Tysoe, Tribol. Trans. 41 (1998) 129.

[3] P.V. Kotvis, L.A. Huezo, W.T. Tysoe, Langmuir 9 (1993) 467.

[4] L. Huezo, P.V. Kotvis, C. Crumer, C. Soto, W.T. Tysoe, Appl. Surf. Sci. 78 (1994) 113.

[5] J. Lara, W.T. Tysoe, Tribol. Letts. 6 (1999) 195.

[6] G. Wu, F. Gao, M. Kaltchev, J. Gutow, J. Mowlem, W.C. Schramm, P.V. Kotvis, W.T. Tysoe, Wear 252 (2002) 595.

[7] F. Gao, P.V. Kotvis, W.T. Tysoe, Tribol. Letts. 15 (2003) 327.

[8] R.W.G. Wyckoff, Crystal Structures, Wiley, New York, 1963.

[9] F.P. Bowden, D. Tabor, The Friction and Lubrication of Solids, Oxford University Press, London, 1964.

[10] R. Holm, Electrical Contacts, Springer, New York, 1967.

[11] A.J. Moses, Handbook of Electronic Materials, vol. 1, IFI/Plenum Press, New York, 1971.

[12] S. Musikant, Optical Materials, Marcel Dekker, New York, 1985.

[13] F. Gao, M. Kaltchev, P.V. Kotvis, W.T. Tysoe, Tribol. Letts. 14 (2003) 99.

[14] T.W. Scharf, I.L. Singer, Tribol. Trans. 45 (2002) 363.

[15] J.M. Martin, C. Grossiord, T. Le Mogne, J. Igarashi, Wear 245 (2000) 107. 
[16] P.V. Kotvis, W.T. Tysoe, Appl. Surf. Sci. 40 (1989) 213.

[17] P.V. Kotvis, W.S. Millman, L. Huezo, W.T. Tysoe, Wear 147 (1991) 401.

[18] P.V. Kotvis, M.N. James, W.T. Tysoe, Wear 153 (1992) 305.

[19] T.J. Blunt, P.V. Kotvis, W.T. Tysoe, Tribol. Letts. 2 (1996) 221.

[20] J. Lara, P.V. Kotvis, W.T. Tysoe, Tribol. Letts. 3 (1997) 303.

[21] K.L. Johnson, Contact Mechanics, Cambridge University Press, Cambridge, UK, 2001.

[22] W.J. Wytenburg, R.M. Lambert, J. Vac. Sci. Technol. 10 (1992) 3579.

[23] X.L. Zhang, B. Prakesh, W. Lauwerens, X.D. Zhu, J.W. He, J.P. Celis, Tribol. Letts. 13 (2003) 131.

[24] C. Grossiord, J.M. Martin, T. Le Mogne, T. Palermo, Tribol. Letts. 6 (1999) 171.
[25] C. Donnet, T. Le Mogne, J.M. Martin, Surf. Coat. Technol. 62 (1993) 406.

[26] C. Donnet, J.M. Martin, T. Le Mogne, M. Belin, Tribol. Int. 29 (1996) 123.

[27] M.L. Suominen Fuller, L. Rodriguez Fernandez, G.R. Massoumi, W.N. Lennard, M. Kasrai, G.M. Bancroft, Tribol. Letts. 8 (2000) 187.

[28] L. Taylor, A. Dratva, H.A. Spikes, Tribol. Trans. 43 (2000) 469.

[29] F.X. Wang, Y.X. Wu, Y.Q. Cheng, B. Wang, S. Danyluk, Tribol. Trans. 39 (1996) 392.

[30] K.L. Johnson, in: W.T. Koiter (Ed.), Theoretical and Applied Mechanics, North Holland Publishing, Amsterdam, 1977, p. 133. 